In the last case any irritation that may ari:e is due more to the roughened skin and the retention of tears than to the lashes themselves. Destruction of the conjunctival mueous membrane will cause the lashes to turn jnwards, just as destruction of the skin of the eyelid will draw them outwards; inversion of lids is, however, often caused by spasmodic closure of the eye, such as is occasioned by the irritation of an operation, or the impact of a foreign body. When the eyeball falls backwards in the socket from absorption of orbital fat, a condition frequently observed in aged persons, the eyelids from loss of support frequently turn inwards. This happens invariably after extirpation of the eyeball, and is only to be remedied by an artificial globe. Any tendency to inversion is of course much exaggerated if the patient forcibly closes the lids, or is iojudiciously bandaged, and this accident frequently complicates the results in cataract operations. The accompanying woodeut

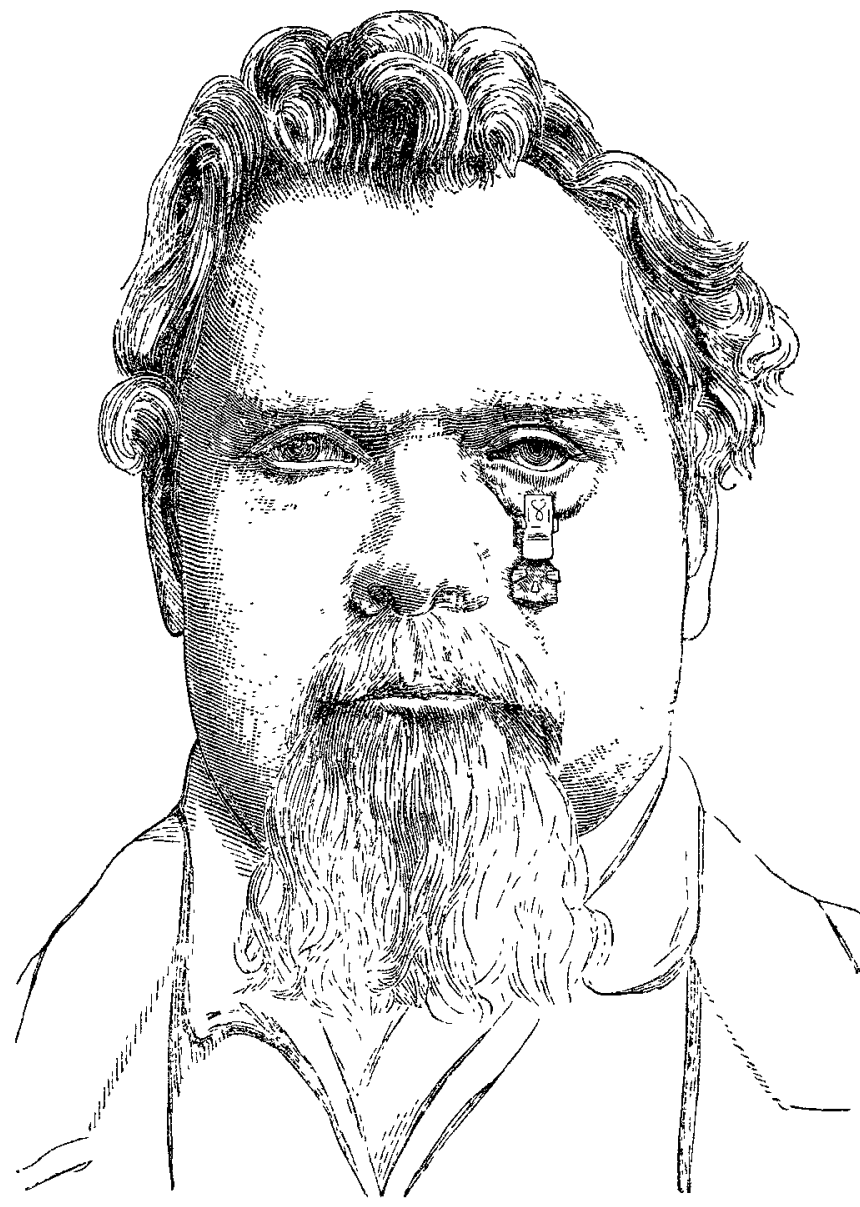

represents a patient who has undergone the operation of extraction for cataract in both eyes. The right, which was operated upon in an ophthalmic institution elsewhere, was lost from subsequent inflammation, due in great measure to the persistent irritation occasioned by inturned lashes; the left was operated upon by myself in February this year, and it was to remedy a similar condition that the steel clip therein depicted was applied.

Various remedies and methods of treating this condition have been recommended and adopted by surgeons from time immemorial : collodion, sticking plaster, bandaging with pads, or by operative procedure either by single or double suture, or the excision of a portion of skin. The first have the disadvantage of being ineffectual, and the second are objected to by the patient as involving another operation and additional pain ; in fact, several patients have assured me that the excision of a piece of skin was more painful than the operation of extraction for cataract itself. In view of these facts, it has appeared to me that a simple method of preventing the inturning of the lashes was a desideratum, and I have for some time past adopted the use of a simple clip, such as is depicted in the engraving, which is painless and at the same time effectual; in fact, the patient had worn the instrument some weeks when his photograph was taken. Not only is inversion at once relieved, bat by wearing the instrument for a short time the patients are frequently cured. Even when this is not the case, and it becomes necessary to remove a portion of skin, the excision of tissue which has been for some time compressed is comparatively painless, and patients do not object to an operation so much after recovery of sight and health and spirits as they do when suffering from the depressing effects of a recest cataract operation, which may or may not turn out well. In dismiesing patien's after operation, if I see any tendency to inversion of the lids I give them one of thess simple instruments with instructions how to $u=e$ it in case of necessity, and have found in a few instances that the evil results of inversion have thus been averted.

Nottingham.

\section{ON A CASE OF}

\section{DELIRIUM TREMENS ASSOCTATED WITH MUCO-ENTERITIS, CLOSELY SIMULATING TYPHOID FEVER.}

\section{By J. T. DILLON, M.D., M.CH.}

THE following notes of a case of delirium tremens with unusually severe complications, ending in recovery, are of interest in some respects. The patient, a man in easy circumstances, aged about forty-five years, up to the date of the present attack always enjoyed good health. $\mathrm{He}$ was of steady and temperate habits till within about four or five months of his present illness, when he sustained a great domestic bereavement by the death of a member of his family to whom he was deeply attached. Since then he had drunk very freely, but being a man of a splendid physique and of robust constitution, he did not appear to have suffered much from his over-indulgence till about two or three weeks before he came under my treatment, when he began to suffer from occasional attacks of vomiting and diarrhoea, with entire loss of appetite. Sleep, too, began to forsake him, and when I was called to see him I found him, after a restless night, wandering, incoherent, and delirious. His pulse, feeble, was 130 ; temperature $102^{\circ}$; tongue covered with brown fur, red at tip and edges; conjunctiva and skin deeply jaundiced; there was slight tympanites with diarrhcea and painful tenesmus. I ordered him opiate draughts with milk and lime-water, and bismuth. After giving the opiates a fair trial, and they failing to procure any sleep, the pulse, too, becoming quicker and more feeble, I put him on ether and digitalis. This had a decidedly beneficial action on his circulation, and I now prescribed hydrate of chloral with bromide of potassium; this, too, after a fair trial, failed in procuring any rest, and I now had recourse to the subcutaneous injection of one grain of morphia, which succeeded admirably in securing him a tranquil sleep of several hours. He awoke quite refreshed, was perfectly intelligent, and answered every question in a rational manner. I now found almost the entire left lung and the base of the right in a state of hepatisation. The diarrhoea still continued, notwithstanding all the opium he had taken; the motions were small in quantity (characteristic feature of typhoid), accompanied with severe pain and very troublesome tenesmus. There were a few rose-coloured spots over the back, and were it not for the information derived from the history of the case, the absence of iliac tenderness, and the aid derived from the thermometer, I should have been inclined to think by this time that I had to deal with a case of typhoid fever. I now put him on sulphuric acid and bark, with poultices of Iceland moss applied over the lungs. After eight or nine days resolution began to take place in the lungs, and proceeded slowly. The jaundice and diarrhoea were still present, despite active treatment directed to the latter. He complained of severe pain over the bladder from time to time, which he sometimes referred to the testes. He took plenty of fluid nourishment, and slept well except when troubled with the stools. Aiter treatment extending over a fortnight, the tongue being clean, the pulse and temperature normal, and the skin and conjunctiva having resumed their normal hue, I put him on solid food; this had the effect of reducing the number of motions from a dozen or more in the twenty.four hours to three or four. They now rapidly resumed their natural appearance, and convalescence became quickly established.

There are many features of interest in this case. The uncontrollable diarrhoea associated with jaundice of hepatic origin is extremely rare. The case presented many of the symptoms of typhoid fever. The extensive and insidious nature of the pulmonary affection are points worthy of con- 
sideration. There were no symptoms present at any time to direct attention to the chest-neither pain, cough, dyspnoea, nor expectoration.

The case was a severe and complicated one throughout, all the symptoms were brought on by free living, the jaundice and diarrhoa being the fruits of a troublesome gastro-duodenal and intestinal catarrh.

Listowel.

\section{ON A CASE OF HYDROPHOBIA.}

BY W. MITCHELL ROOCROFT, M.R.C.S., \&c., HONORARY SURGEON TO THE ROYAL ALBERT EDWARD INFIRMARY, WIGAN.

HydRophoBIA being a disease of comparative rarity, I venture to hope that the following notes of a case occurring in my practice may be of interest.

John F-_ aged twenty-eight years, a groom and coachman, was bitten by a bloodhound bitch on June 21st, 1883. He was a steady and temperate man, having previously enjoyed good health, but of nervous temperament. I saw the patient next day. He was suffering from mental anxiety, and had a punctured and lacerated wound on the upper lip, which had been thoroughly cauterised with nitrate of silver by a surgeon, to whom he had immediately hurried upon receipt of the injury. At the urgent request of the patient, I examined the bitch. I found her chained up, and with difficulty induced her to leave the kennel, as she seemed to shun the light, and was dull, but snappish. The coat was staring, and the abdomen tucked up. Appetite was lost, lat evidently she could drink without much difficulty. I detected no modification in the bark, and although her head was depressed, the jaw had not dropped from paralysis. She had bitten fox terrier dog on the previous day. I advised that the animal be removed to an adjoining kennel, where she could be watched and prevented from inflicting further harm, but not to destroy her. Although the synutoms were those of incipient rabies, I was anxious to watch for the full development of the disease. Unfortunately popular prejudice was too strong, and the bitch was shot the same afternoon. The wound on my patient's lip healed completely, and he seemed to regain his usual health, though his friends remarked that at times he was nervous and depressed. On Sunday, July 29th, it was noticed that the patient was peevish, irritable, and low spirited, complaining of alternate chills and heats, with anorexia. It may here be noticed that the period of incubation or "delitescence" was thirty. eight days; in a previous case under my care the limit was from thirty-nine to forty days. I was sent for hurriedly to see the patient on the morning of August 1st. He had passed a very bad night, having had little or no sleep, repeatedly jumping up with what he termed "bad dreams." The stage of "recrudescence," as it has been termed, was rapidly passing away, and I found him in bed with an anxious expression on his face. There was no redness or irritability about the wound, which presented a healthy cicatrix, and I could not detect any affection of the submaxillary, deep parotid, or cervical lym. phatic glands. He complained of a feeling of oppression about the chest, with severe pains in the epigastrium, due, I thought, to spasm of the diaphragm; but upon ausculta tion $\mathrm{I}$ discovered in addition evidence of acute endocarditis, with a mitral systolic murmur. This murmur increased in intensity as the disease progressed. There was no history of a previous attack of acute articular rheumatism. I noticed involuntary deep sighing jnspirations from time to time. Temperature in axilla $1002^{\circ}$. Tongue dry, but clean bowels regular ; complete anorexia; pulse regular, but laboured; face flushed; head hot and aching; only very slight difficulty in swallowing; urine normal, but scanty. I ordered warm applications to the cardiac region and epigastrium, small quantities of strong beef-tea and milk, complete rest and quietness, and the following draught : - Thirty grains of hydrate of chloral, thirty grains of bromide of potassium, half a drachm of tincture of digitalis, in ar ounce of orange water. $\mathrm{He}$ was seen again in the evening, when the symptoms were about the same, but he had had a little sleep, and was quieter; had swallowed a little beef-tea, but was becoming more thirsty. The draught, to be repeated.-August 2od : Much worse since 5 A.M.; no sleep; expression of face intensely anxious and much flushed. Temperature $101^{\circ}$. Is bathed in a profuse perspiration; mitral murmur intensified; pulse weak, and almost uncountable. He cannot now swallow, owing to the spasmodic action of the muscles of deglutition and respiration; in fact, the very sight of water, and his hearing me pour out a draught containing thirty grains of bromide of potassium and half a drachm of tincture of cannabis indicus, was sufficient to bring on a most agonising spasm. These attacks were accompanied by fits of violent mania, during which it was almost impossible to keep him in bed, followed by intervals when the intelleet was quite clear. During these remissions I discovered that when I induced him to shut his eyes he could swallow small quantities of the draught without much difficulty. I now ordered ice-bags to be applied along the spine, the room to be completely darkened, and the bed surrounded by light curtains, for I noticed that hyperæsthesia of the surface and of the special organs was rapidly manifesting itself. $\mathrm{He}$ gradually became worse, and appealed piteously for those in the room not to move or cause any draught, theslightest movement or breath of air being sufficient to bring on most frightful spasms of the muscles of deglutition and respiration, the diaphragm being in a state of intense clonic spasm. Thirst was now most agonising, and his mouth, dry and parched, was constantly filling with viscid, clammy saliva, the efforts to expectorate which only increased the frequency of the spasms. The condition of the patient was rapidly becoming worse, and I felt that the condition of his heart would not justify me in the administration of chloroform by inhalation (a course I adopted in my previous case, but with no better result), so at 11 A.M. I gave half a grain of morphia hypodermically. It was not until twelve o'clock that the morphia had any appreciable sedative effect. The patient gradually sank and died at 1.45 P.M. the same day from syncope. I regret that I was unable to obtain a post-mortem examination of the body.

In conclusion, I may mention that the fox-terrier bitten by the same bloodhound died from acute rabies on the same afternoon as my patient. I am unable to account satisfactorily for the etiology of the acute endocarditis in this case. It may have been merely an accidental coincidence. I am afraid my case only illustrates too painfully our present inability to ward off a fatal issue in this dreadful disease.

Wigan.

\section{AMENORRHGEA DEPENDING ON ABSENCE OF THE UTERUS.}

BY J. L. VAN GEYZEL, M.B., C.M., SURGEON, INDIAN MEDICAL DEYARTMENT.

ThE social consequences to a married Brahmin female of the existence of any bar to pregnancy are, I believe, of a far more serious nalure in India than in any other country in the world. The Brahmin law provides for the perpetuation of families by permitting a man to take a second wife when a first wife has no issue after a reasonable period of married life; this is always taken advantage of, so that it is not difficult to surmise the relative position of the first wife in such a household, where she would be treated as the "waiting maid," if she does not return to her friends to live in disgrace and widowhood. Apart from this interest in a case, where an opinion fraught with such serious consequences should be well considered and weighed, the rarity of the occurrence of instances of absence of the uterus, discovered during life, has induced me to record the following notes of a case which I was asked to see by the civil sur. geon:-

A. B-, a Brahmin female, married, aged twenty years, sought advice on account of sterility, stating at the same time that there was some obstacle to complete sexual intercourse. Previous history as related by the civil sur. geon :-General health has always been good; but she has never menstruated, though since April, 1882, she has experienced, from time to time, symptoms known as "the menstrual molimen." What the consummate ignorance of native hakeems and barber women could accomplish was resorted to before applying for European advice, and she had been advised to try to dilate the uretbra, as the small size of the vagina was thought to be the cause of sterility. By means of pieces of pith she had succeeded in dilating the urethra, and no doubt intercourse took place through 